\title{
SISTEM INFORMASI AKUNTANSI DAN PENGENDALIAN INTERNAL TERHADAP EFEKTIVITAS PENJUALAN
}

\author{
Iyab Salahudin ${ }^{1}$, Gatot Wahyu Nugroho ${ }^{2}$, Tina Kartini ${ }^{3}$ \\ Universitas Muhammadiyah Sukabumi ${ }^{1,2,3}$ \\ salahudiniyab@gmail.com ${ }^{1}$
}

\begin{abstract}
ABSTRAK
Tujuan penelitian ini adalah untuk mengetahui efektivitas penjualan di koperasi Darussyfa Mart berdasarkan sistem informasi akuntansi dan pengendalian internal. Penelitian ini menggunakan metode kuantitatif dengan jenis pendekatan assosiatif. Pengambilan sampel dilakukan secara nonprobability sampling dengan teknik purpose sampling. Hasil penelitian menunjukan bahwa variasi sistem informasi akuntansi dan pengendalian internal memiliki pengaruh terhadap efektivitas penjualan sebesar $31,7 \%$ dan sisanya dipengaruhi oleh faktor lain. Simpulan, $X_{1}$ (sistem informasi akuntansi penjualan) memiliki pengaruh yang lebih besar terhadap efektifitas penjualan (Y) dibandingkan $\mathrm{X}_{2}$ (pengendalian internal). Namun variabel $\mathrm{X}_{1}$ dan $\mathrm{X}_{2}$ secara bersamasama memiliki pengaruh yang signifikan terhadap efektivitas penjualan di Darussyfa Mart. Kemampuan variabel-variabel independen $\left(\mathrm{X}_{1}\right.$ dan $\left.\mathrm{X}_{2}\right)$ dalam menjelaskan variasi variabel dependen (Y) adalah sebesar 31,7\%, sedangkan sisanya sebesar 68,3\% dipengaruhi oleh faktor lain di luar model ini yang tidak diteliti.
\end{abstract}

Kata Kunci: Efektivitas Penjualan, Pengendalian Internal, Sistem Informasi Akuntansi

\section{ABSTRACT}

The purpose of this study was to determine the effectiveness of sales in the Darussyfa Mart cooperative based on accounting information systems and internal controls. This study uses a quantitative method with an associative approach. Sampling was done by nonprobability sampling with a purposive sampling technique. The results showed that variations in accounting information systems and internal control had an effect on sales effectiveness by $31.7 \%$ and the rest was influenced by other factors. In conclusion, $X_{1}$ (sales accounting information system) has a greater influence on sales effectiveness $(Y)$ than $X_{2}$ (internal control). However, the variables $X_{1}$ and $X_{2}$ together have a significant influence on the effectiveness of sales at Darussyfa Mart. The ability of the independent variables $\left(X_{1}\right.$ and $\left.X_{2}\right)$ in explaining the variation in the dependent variable $(Y)$ is $31.7 \%$, while the remaining $68.3 \%$ is influenced by other factors outside this model which are not examined.

Keywords: Sales Effectiveness, Internal Control, Accounting Information Systems 


\section{PENDAHULUAN}

Seiring dengan perkembangan perekonomian saat ini, perdagangan yang ada di Indonesia sudah sangat berkembang. Hal ini menimbulkan persaingan yang semakin ketat, dimana para pelaku usaha tersebut akan berlomba-lomba untuk memenangkan persaingan di dalam pasar. Apabila suatu perusahaan dapat memenangkan persaingan di dalam pasar, maka perusahaan tersebut akan memperoleh pendapatan yang optimal. Agar tujuan tersebut tercapai, maka perusahaan harus terlebih dahulu merencanakan strategi yang dianggap tepat, sesuai yang dibutuhkan oleh perusahaan. Adapun pendapatan tersebut berasal dari hasil penjualan.

Penjualan merupakan salah satu sistem kegiatan pokok perusahaan untuk memperjualbelikan barang dan jasa yang perusahaan-perusahaan hasilkan (Sujarweni, 2015). Sistem yang diperlukan oleh perusahaan dalam penjualan barang dengan cara mewajibkan pembeli untuk melakukan pembayaran harga terlebih dahulu sebelum barang diserahkan pada pembeli. Setelah pembeli melakukan pembayaran, barang diserahkan, kemudian transaksi penjualan dicatat. Kegiatan penjualan dalam perusahaan merupakan aktivitas yang sangat penting dalam kelangsungan suatu perusahaan, dimana kegiatan penjualan tersebut akan menghasilkan laba yang bisa di pergunakan untuk aktivitas perusahaan saat ini maupun di masa yang akan datang. Tetapi jika di dalam aktivitas perusahaan khususnya dalam proses penjualan yang kurang efektif, maka perusahanan akan mengalami penurunan atas laba yang di harapkan dan bisa saja perusahaan mengalami kerugian yang akan berdampak buruk terhadap penjualan perusahaan.

Dalam mengatasi masalah ini diperlukan adanya suatu sistem yang menyediakan informasi penjualan, yakni sistem informasi akuntansi penjualan. Sistem informasi akuntansi adalah suatu komponen organisasi yang menumpulkan, menggolongkan, mengolah, menganalisa dan mengkomunikasikan informasi keuangan yang relevan untuk mengambil keputusan kepada pihak-pihak luar (seperti inspeksi pajak, investor dan kreditur) dan pihak-pihak dalam terutama menejemen (Zamzami et al., 2016).

Suatu sistem informasi akuntansi penjualan akan dapat berjalan dengan baik dan lancar apabila adanya suatu pengendalian internal didalam sistem tersebut. Pengendalian tersebut dimaksudkan agar tidak terjadi hal-hal yang tidak diinginkan seperti kecurangan-kecurangan dan kesalahan-kesalahan yang tidak diinginkan tersebut 
dapat teratasi. Adapun pentingnya penerapan sistem informasi akuntansi penjualan agar dapat meningkatkan penjualan yang efektif bagi perusahaan tersebut.

Darussyfa Mart yang sering disebut dengan koperasi merupakan unit usaha yang dimiliki oleh perguruan Yaspida Sukabumi badan usaha yang mencukupi kebutuhan siswa khususnya makanan, minuman, peralatan makan dan peralatan mandi. Darussyfa Mart pada awalnya dimulai pada tahun 2001 dari tahun ke tahun jumlah Darussyfa Mart yang awalnya sederhana dan hanya ada satu, sekarang sudah bisa berjalan dan mendirikan beberapa unit. Hingga tahun 2020, unit usaha ini telah memiliki 9 unit.

Dalam observasi yang dilakukan pada tanggal 4 Januari 2020, mengenai proses penjualan pada Darussyfa Mart ditemukan beberapa permasalahan yang terjadi diantaranya: sering terjadinya salah catat dikarenakan pencatatan dalam penyusunan laporan keuangan sebagian masih mengunakan manual. Dokumen prosedur penjualan seperti bukti transaksi penjualan dan faktur penjualan tidak memiliki arsip untuk pencatatan akuntansi serta sering terjadi rangkap jabatan antara keuangan dengan bagian administrasi. Berbeda dengan penelitian terdahulu yang telah dilakukan oleh Wahyuningsih et al., (2015) terhadap Perusahaan Daerah Air Minum (PDAM) Kabupaten Malang, menunjukkan bahwa sistem perusahaan telah sesuai dengan tahaptahap audit operasional yang terdiri dari audit pendahuluan, tahap audit mendalam dan tahap pelaporan. Adanya struktur organisasi perusahaan dan uraian tugas dengan jelas sehingga wewenang dan tanggung jawab masing-masing bagian menjadi jelas.

\section{KAJIAN TEORI}

\section{Sistem Informasi Akuntansi}

Sistem informasi akuntansi adalah sebuah komponen atau kejelasan alat untuk mengumpulkan, mencatat, menyimpan, dan memproses akuntansi dan data lain untuk menghasilkan informasi bagi pembuat keputusan (Romney \& Steintbart, 2015). Sistem informasi akuntansi adalah sutau komponen organisasi yang mengumpulkan, menggolongkan, mengolah, menganalisis dan mengkomunikasikan informasi keuangan yang relevan untuk pengambilan keputusan kepada pihak-pihak luar (seperti inspeksi, pajak, investor dan kreditur) dan pihak-pihak dalam terutama manajemen (Zamzami et al., 2016). 
Berdasarkan definisi di atas dapat disimpulkan bahwa sistem informasi akuntansi adalah sebuah sistem informasi yang diperlukan oleh perusahaan, dimana sistem tersebut dapat berfungsi sebagai pengolah data, penyimpan data dan sebagai penghasil informasi keuangan yang dibutuhkan oleh perusahaan yang pada akhirnya dapat digunakan sebagai dasar dalam pengambilan keputusan penting dalam bidang perusahaan.

\section{Efektivitas}

Efektivitas adalah ukuran berhasil tidaknya suatu organisasi mencapai tujuanya. Apabila suatu organisasi berhasil mencapai tujuan, maka organisasi tersebut telah berjalan dengan efektif (Halim, 2012). Efektivitas merupakan hubungan antara hasil yang diharapkan dengan hasil yang sesungguhnya dicapai. Efektivitas merupakan hubungan antara output dengan tujuan. Semakin besar kontribusi output terhadap pencapaian tujuan, maka semakin efektif organisasi, program atau kegiatan (Mahmudi 2010). Berdasarkan definisi-definisi efektivitas tersebut dapat disimpulkan bahwa efektivitas adalah ukuran berhasil tidaknya tujuan yang ingin dicapai oleh suatu organisasi atau kegiatan lainnya.

\section{Penjualan}

Penjualan adalah suatu sistem kegiatan pokok perusahaan untuk memperjual belikan barang dan jasa yang perusahaan hasilkan (Sujarwerni 2015). Penjualan adalah ilmu seni mempengaruhu pribadi yang di lakukan oleh penjual untuk mengajak orng lain agar bersedia membeli barang/jasa yang ditawarkan (Swastha, 2012).

Berdasarkan pengertian diatas, maka penulis dapat menyimpulkan bahwa penjualan adalah kegiatan yang sangat diperlukan, karana dengan penjualan perusahaan mendapatkan laba yang nantinya akan di pergunakan untuk aktivitas perusahaan. 


\section{METODE PENELITIAN}

Metode yang digunakan oleh peneliti dalam melakukan penelitian ini adalah menggunakan metode kuantitatif dengan jenis pendekatan assosiatif. Metode kuantitatif dapat diartikan sebagai metode penelitian yang berlandaskan pada filsafat possitivisme dan digunakan untuk meneliti pada populasi atau sampel tertentu, pengumpulan data menggunakan instrument penelitian, analisis data bersifat kuantitatif/statistik, dengan tujuan untuk menguji hipotesis yang telah di tetapkan (Sugiyono, 2017).

Populasi dalam penelitian ini adalah 192 karyawan di Darussyfa Mart. Populasi adalah wilayah generalisasi yang terdiri atas objek atau subjek yang mempunyai kualitas dan karakteristik tertentu yang di tetapkan oleh peneliti untuk dipelajari dan kemudian ditarik kesimpulannya. Teknik pengambilan sampel yang digunakan dalam penelitian ini adalah nonprobability sampling dengan teknik purpose sampling. Nonprobability sampling adalah teknik pengambilan sampel yang tidak memberi peluang atau kesempatan sama bagi setiap unsur atau anggota populasi untuk dipilih menjadi sampel. Penentuan sampel pada penelitian ini menggunakan purpose sampling, yaitu penarikan sampel dengan pertimbangan tertentu yang didasarkan pada kepentingan atau tujuan penelitian (Sugiyono, 2017). Adapun sampel penelitian ini adalah 130 karyawan di Darussyfa Mart.

Teknik pengumpulan data yang digunakan dalam penelitian ini yaitu data primer dan data sekunder. Data primer menjadi data utama dan dan data sekunder sebagai data pendukung. Pengumpulan data dilakukan oleh peneliti melalui observasi dan kusioner. Pada hakikatnya, pengumpulan data dapat dilakukan dalam berbagai setting, sumber dan cara.

Penelian ini memiliki tiga variabel yang dijadikan objek penelitian yaitu: 1) sistem informasi akuntansi penjualan (variabel $\mathrm{X}_{1}$ ); 2) pengendalian internal (variabel $\mathrm{X}_{2}$ ); 3) efektivitas penjualan (variabel $\mathrm{Y}$ ). Penelitian ini ditunjukkan untuk menjelaskan kedudukan-kedudukan variabel yang akan diteliti serta hubungan antara satu variabel dengan variabel yang lain atau untuk melihat hubungan variabel sistem informasi akuntansi penjualan dan pengendaian internal terhadap variabel dependen yaitu efektivitas penjualan Darussyfa Mart.

Analisis data yang digunakan dalam penelitian ini adalah analisis kuantitatif dengan menggunakan teknik perhitungan statistik. Analisis data yang diperoleh dalam 
penelitian ini akan dianalisis menggunakan program SPSS 24. Metode analisis data yang digunakan dalam penelitian ini adalah dengan metode analisis regresi linier berganda.

\section{HASIL PENELITIAN}

Data Primer Kuesioner

Tabel 1.

Bobot Nilai Kuisoner

\begin{tabular}{|c|c|c|}
\hline No. & Keterangan & Bobot Nilai \\
\hline 1 & Sangat Setuju & 5 \\
\hline 2 & Setuju & 4 \\
\hline 3 & Cukup setuju & 3 \\
\hline 4 & Tidak Setuju & 2 \\
\hline 5 & Sangat Tidak Setuju & 1 \\
\hline
\end{tabular}

(Sumber: Data Diolah Penulis, 2020)

Populasi dalam penelitian ini adalah semua karyawan yang ada di Darussyfa Mart Berjumlah 192 orang, sedangkan yang menjadi sampel adalah manager, staff dan anggota berjumlah 130 orang.

Berdasarkan bobot nilai kuesioner yang telah diuraikan diatas, berikut penulis sajikan hasil skor kuesioner untuk kedua variabel pada penelitian ini.

Tabel 2.

Hasil Skor Variabel $\mathbf{X}_{\mathrm{I}}$

\begin{tabular}{|c|c|c|c|c|c|c|c|c|c|}
\hline \multicolumn{10}{|c|}{ Pilihan Jawaban } \\
\hline Variabel & No. & $\begin{array}{c}\text { STS } \\
\text { (1) }\end{array}$ & $\begin{array}{l}\text { TS } \\
\text { (2) }\end{array}$ & $\begin{array}{l}\text { CK } \\
\text { (3) }\end{array}$ & $\begin{array}{c}S \\
(4)\end{array}$ & $\begin{array}{l}\text { SS } \\
\text { (5) }\end{array}$ & $\mathbf{N}$ & $\begin{array}{l}\text { Total } \\
\text { Skor }\end{array}$ & $\begin{array}{l}\text { Rata- } \\
\text { Rata }\end{array}$ \\
\hline \multirow{16}{*}{$\begin{array}{c}\text { Sistem } \\
\text { Informasi } \\
\text { Akuntansi } \\
\text { Penjualan } \\
\quad\left(\mathrm{X}_{1}\right)\end{array}$} & 1 & 2 & 12 & 30 & 52 & 34 & 130 & 494 & 3,8 \\
\hline & 2 & 7 & 22 & 19 & 53 & 29 & 130 & 465 & 3,57 \\
\hline & 3 & 7 & 22 & 16 & 56 & 29 & 130 & 193 & 1,48 \\
\hline & 4 & 14 & 12 & 20 & 51 & 32 & 130 & 462 & 3,55 \\
\hline & 5 & 6 & 21 & 21 & 61 & 21 & 130 & 460 & 3,53 \\
\hline & 6 & 8 & 21 & 21 & 48 & 32 & 130 & 465 & 3,57 \\
\hline & 7 & 12 & 22 & 21 & 46 & 29 & 130 & 448 & 3,44 \\
\hline & 8 & 9 & 15 & 14 & 58 & 34 & 130 & 483 & 3,71 \\
\hline & 9 & 9 & 19 & 10 & 44 & 48 & 130 & 493 & 3,79 \\
\hline & 10 & 17 & 22 & 15 & 50 & 26 & 130 & 436 & 3,35 \\
\hline & 11 & 14 & 26 & 22 & 30 & 38 & 130 & 442 & 3,4 \\
\hline & 12 & 10 & 27 & 16 & 33 & 44 & 130 & 464 & 3,56 \\
\hline & 13 & 9 & 21 & 13 & 45 & 42 & 130 & 480 & 3,69 \\
\hline & 14 & 14 & 25 & 19 & 24 & 48 & 130 & 457 & 3,51 \\
\hline & 15 & 7 & 17 & 12 & 57 & 37 & 130 & 490 & 3,76 \\
\hline & 16 & 7 & 17 & 18 & 51 & 37 & 130 & 466 & 3,58 \\
\hline \multicolumn{9}{|c|}{ Jumlah Persentase (\%) } & $55,29 \%$ \\
\hline
\end{tabular}

(Sumber: Data Primer yang Diolah Penulis, 2020) 
Berdasarkan tabel 2, responden menyatakan setuju bahwa sistem informasi akuntansi penjualan memiliki pengaruh kuat terhadap penjualan Darussyfa Mart. Hal ini terlihatdari hasil kuisoner di atas yang menunjukkan jawaban responden lebih dominan setuju (S).

Tabel 3.

Hasil Skor Variabel Y

\begin{tabular}{cccccccccc}
\hline & \multicolumn{8}{c}{ Pilihan Jawaban } \\
\hline \multirow{2}{*}{ Variabel } & No. & $\begin{array}{c}\text { STS } \\
(\mathbf{1})\end{array}$ & $\begin{array}{c}\text { TS } \\
\mathbf{( 2 )}\end{array}$ & $\begin{array}{c}\text { CK } \\
\mathbf{( 3 )}\end{array}$ & $\begin{array}{c}\text { S } \\
\mathbf{( 4 )}\end{array}$ & $\begin{array}{c}\text { SS } \\
\mathbf{( 5 )}\end{array}$ & $\mathbf{N}$ & $\begin{array}{c}\text { Total } \\
\text { Skor }\end{array}$ & $\begin{array}{c}\text { Rata- } \\
\text { Rata }\end{array}$ \\
\hline & 1 & 7 & 11 & 13 & 51 & 48 & 130 & 512 & 3,39 \\
Efektivitas & 2 & 9 & 16 & 14 & 49 & 42 & 130 & 429 & 3,3 \\
Penjualan & 3 & 4 & 18 & 6 & 55 & 47 & 130 & 513 & 3,94 \\
(Y) & 4 & 5 & 9 & 15 & 44 & 57 & 130 & 529 & 4,06 \\
& 5 & 6 & 20 & 11 & 56 & 37 & 130 & 488 & 3,75 \\
& 6 & 11 & 25 & 16 & 43 & 35 & 130 & 456 & 3,50 \\
\hline \multicolumn{8}{c}{ Jumlah Persentase }
\end{tabular}

(Sumber: Data Primer yang Diolah Penulis, 2020)

Berdasarkan tabel 3, hasil kuisoner menunjukkan bahwa responden paling banyak menyatakan setuju (S), dimana variabel Y memiliki pengaruh yang kuat dalam Darussyfa Mart.

\section{Prosedur Sistem Informasi Akuntansi Penjulan di Darussyfa Mart}

Berikut merupakan prosedur sistem informasi akuntansi yang dimiliki oleh Darussyfa Mart, terdiri dari tiga bagian yaitu, bagian customer, kasir dan gudang.
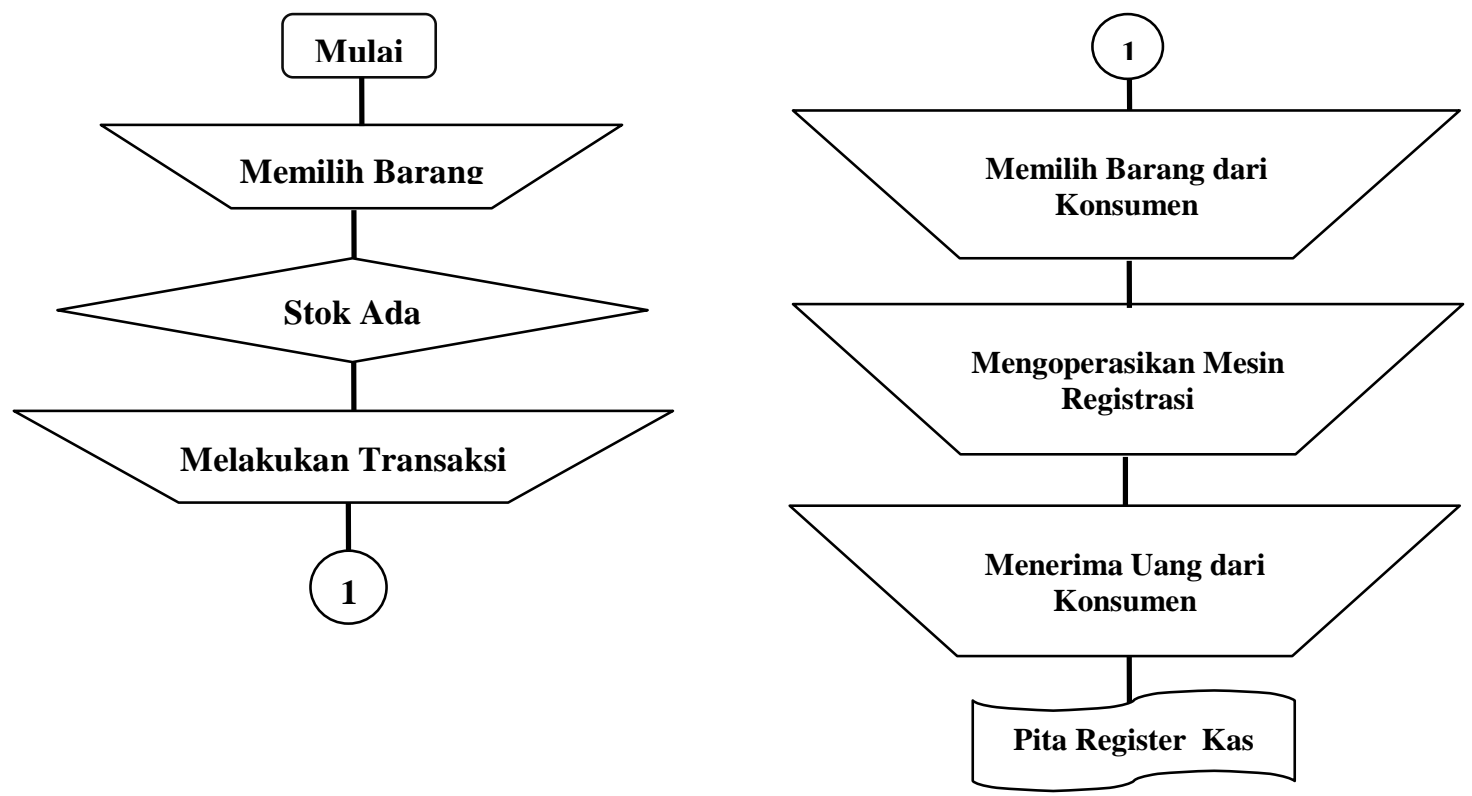

Gambar 1.

Bagan Alir Bagian Customer 

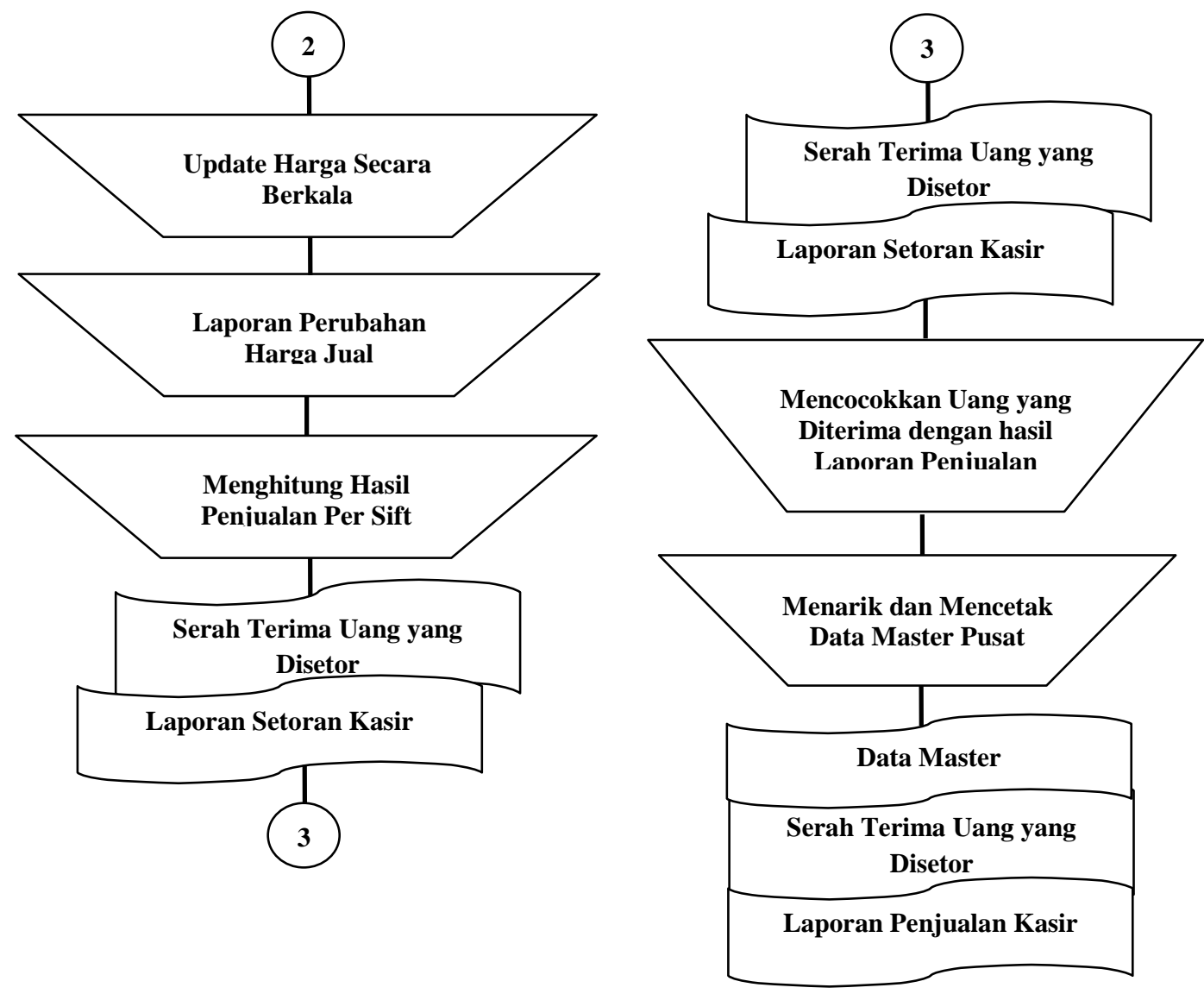

Gambar 2.

Bagan Alir Bagian Kasir

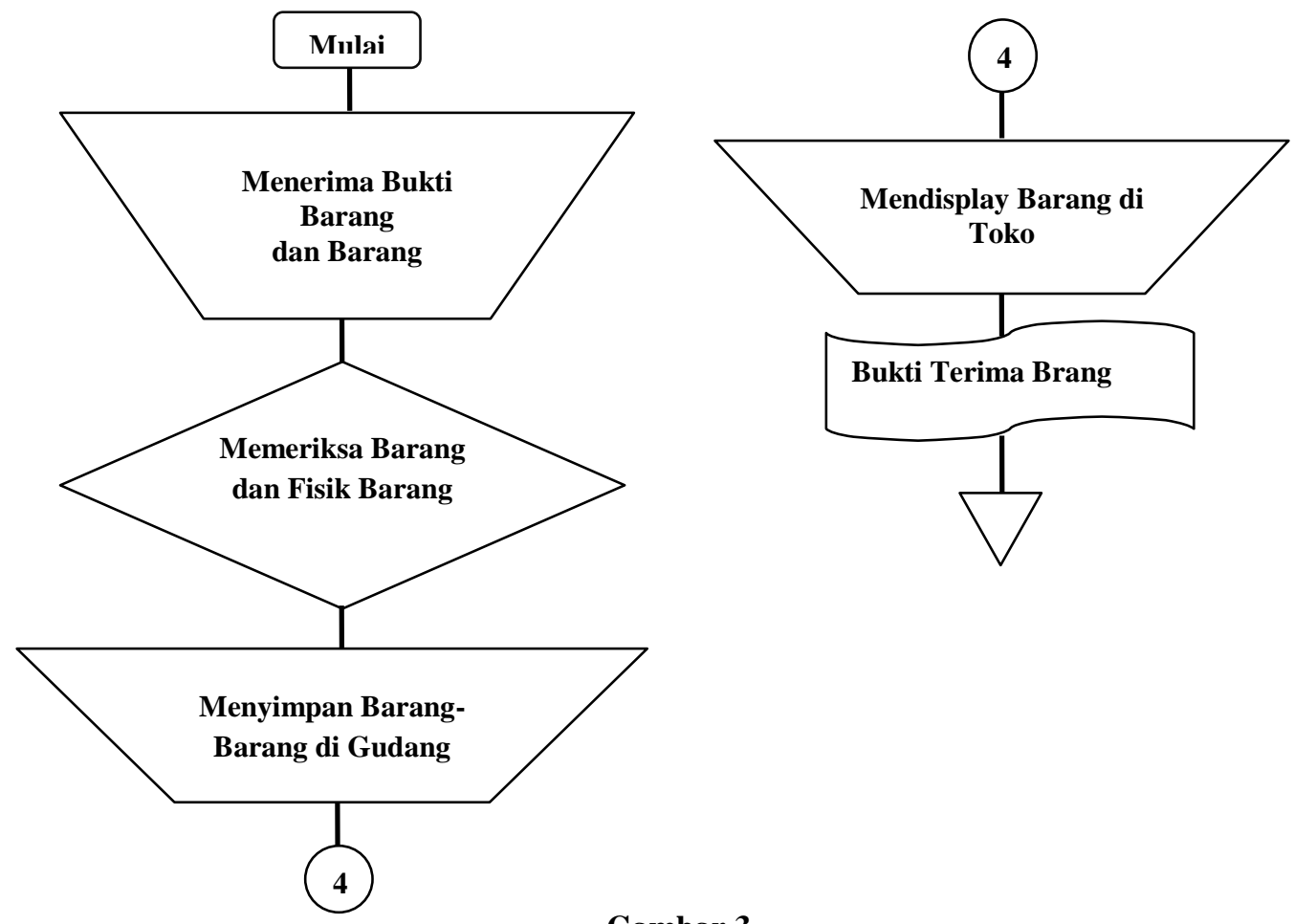

Gambar 3.

Bagan Alir Bagian Gudang 


\section{Uji Normalitas}

Tabel 4.

Hasil Uji Normalital

\begin{tabular}{|c|c|c|}
\hline \multicolumn{3}{|c|}{ One-Sample Kolmogorov-Smirnov Test } \\
\hline \multirow{2}{*}{\multicolumn{2}{|c|}{$\mathbf{N}$}} & Unstandardized Residual \\
\hline & & 130 \\
\hline \multirow{2}{*}{$\begin{array}{l}\text { Normal } \\
\text { Parameters }\end{array}$} & Mean & .000 \\
\hline & Std. Deviation & 3.506 \\
\hline \multirow{3}{*}{$\begin{array}{l}\text { Most Extreme } \\
\text { Differences }\end{array}$} & Absolute & .056 \\
\hline & Positive & .055 \\
\hline & Negative & -.056 \\
\hline \multicolumn{2}{|l|}{ Test Statistic } & .056 \\
\hline \multicolumn{2}{|l|}{ Asymp. Sig. (2-Tailed) } & $200^{\mathrm{c}, \mathrm{d}}$ \\
\hline \multicolumn{3}{|c|}{ a. Test Distribution is Normal } \\
\hline \multicolumn{3}{|c|}{ b. Calculate from Data } \\
\hline \multicolumn{3}{|c|}{ c. Lilliefors Significance Correct } \\
\hline \multicolumn{3}{|c|}{ d. This is a Lower Bound of the True Significance } \\
\hline
\end{tabular}

(Sumber: Data Diolah Penulis menggunakan Software SPSS 24 for Windows, 2020)

Berdasarkan tabel 4, dapat diketahui bahwa data sampel yang diambil terdistribusi normal dan data hasil penelitian tersebut dapat menggambarkan karakteristik populasinya.

\section{Uji Multikolinearitas}

Uji multikolinearitas digunakan untuk mengukur seberapa pengaruhnya variabel independen terhadap independen lainnya dengan menggunakan regresi tersebut. Pengujian multikolinearitas menggunakan Variance Inflationfactor (VIF) pada soffware SPSS 24 for Window. Berikut merupakan tabel hasil pengujian multikolinearitas:

Tabel 5.

Hasil Uji Multikolinearitas

\begin{tabular}{|c|c|c|c|c|c|c|c|}
\hline \multicolumn{8}{|c|}{ Coeficients $^{a}$} \\
\hline \multirow[t]{2}{*}{ Model } & \multicolumn{2}{|c|}{$\begin{array}{c}\text { Unstandardized } \\
\text { Coefficients }\end{array}$} & \multirow{2}{*}{$\begin{array}{c}\begin{array}{c}\text { Standardized } \\
\text { Coefficients }\end{array} \\
\text { Beta } \\
\end{array}$} & \multirow[t]{2}{*}{$\mathbf{T}$} & \multirow[t]{2}{*}{ Sig. } & \multicolumn{2}{|c|}{$\begin{array}{c}\text { Collinearity } \\
\text { Statistics }\end{array}$} \\
\hline & B & Std. Error & & & & Tolerance & VIF \\
\hline 1 (Constant) & 6.381 & 2.184 & & 2.922 & .004 & & \\
\hline TX1 & .194 & .037 & .416 & 5.323 & .000 & .882 & 1.134 \\
\hline TX2 & .250 & .074 & .263 & 3.374 & .001 & .882 & 1.134 \\
\hline
\end{tabular}

(Sumber: Data Diolah Penulis Menggunakan Software SPSS 24 for Windows, 2020)

Berdasarkan tabel 5, angka tolerance sebesar 0,882 dan VIF sebesar 1,134 artinya $0,882>0,10$ dan $1,134<10$. Jadi, dapat disimpulkan bahwa tidak terdapat 
gejala multikolinearitas antar variabel independen dalam model regresi pada penelitian ini.

\section{Uji Heteroskedastisitas}

Uji heterokedastisitas dilakukan untuk mengetahui apakah dalam model regresi terjadi ketidaksamaan varian dari residual suatu pengamatan ke pengamatan lain. Pengujian ini menggunakan grafik Scatterplot atau niali prediksi variabel terikat. Dengan menggunakan Scatterplot, suatu heterokedastisitas diketahui dengan melihat sebaran plot data. Ketika pada grafik terdapat pola tertentu, seperti titik-titik yang membentuk pola teratur (bergelombang, menebar, kemudian menyempit), maka terjadi heterokedastisitas. Jika tidak ada pola yang jelas, seperti titik-titik menyebar diatas dan di bawah angka nol pada sumbu Y, maka tidak terjadi heterokedasitas.

\section{Hasil Regresi Linear Berganda}

Tabel 6.

Hasil Regresi Linier Berganda

\begin{tabular}{|c|c|c|c|c|c|c|c|}
\hline \multicolumn{8}{|c|}{ Coeficients $^{a}$} \\
\hline \multirow[t]{2}{*}{ Model } & \multicolumn{2}{|c|}{$\begin{array}{c}\text { Unstandardized } \\
\text { Coefficients }\end{array}$} & \multirow{2}{*}{$\begin{array}{c}\begin{array}{c}\text { Standardized } \\
\text { Coefficients }\end{array} \\
\text { Beta }\end{array}$} & \multirow[t]{2}{*}{$\mathbf{T}$} & \multirow[t]{2}{*}{ Sig. } & \multicolumn{2}{|c|}{$\begin{array}{l}\text { Collinearity } \\
\text { Statistics }\end{array}$} \\
\hline & B & Std. Error & & & & Tolerance & VIF \\
\hline 1 (Constant) & 6.381 & 2.184 & & 2.922 & .004 & & \\
\hline TX1 & .194 & .037 & .416 & 5.323 & .000 & .882 & 1.134 \\
\hline TX2 & .250 & .074 & .263 & 3.374 & .001 & .882 & 1.134 \\
\hline
\end{tabular}

a. Dependent Variable: TY

(Sumber: Data Diolah Penulis Menggunakan Software SPSS 24 for Windows, 2020)

Berdasarkan tabel di atas, maka perhitungan di atas mendapat hasil seperti berikut ini: $\mathrm{a}=6.381 ; \mathrm{b}=0.194 ; \mathrm{c}=0.250$, jadi persamaan regresi ganda linier yang terbentuk adalah:

$$
\mathrm{Y}=6.381+(0.194) \mathrm{TX}_{1}+(0.250) \mathrm{TX}_{2}
$$




\section{Uji T}

Pengujian uji $\mathrm{T}$ dilakukan dua cara yaitu quick look dan perbandingan nilai $\mathrm{T}_{\text {hitung }}$ dan $\mathrm{T}_{\text {tabel }}$ dengan hasil sebagai berikut:

Tabel 7.

Hasil Uji T

\begin{tabular}{cccccccc}
\hline Model & \multicolumn{9}{c}{ Coeficients $^{a}$} \\
& $\begin{array}{c}\text { Unstandardized } \\
\text { Coefficients }\end{array}$ & $\begin{array}{c}\text { Standardized } \\
\text { Coefficients }\end{array}$ & T & Sig. & \multicolumn{2}{c}{$\begin{array}{c}\text { Collinearity } \\
\text { Statistics }\end{array}$} \\
\cline { 2 - 4 } & $\mathbf{B}$ & Std. Error & Beta & & & Tolerance & VIF \\
\hline 1 (Constant) & 6.381 & 2.184 & & 2.922 & .004 & & \\
TX1 & .194 & .037 & .416 & 5.323 & .000 & .882 & 1.134 \\
TX2 & .250 & .074 & .263 & 3.374 & .001 & .882 & 1.134 \\
\hline a. Dependent Variable: TY & & & & & \\
\hline
\end{tabular}

(Sumber: Data Diolah Penulis Menggunakan Software SPSS 24 for Windows, 2020)

Berdasarkan data analisis pada tabel 7, maka diperoleh hasil yang menunjukkan bahwa $\mathrm{TX}_{1}$ (sistem informasi akuntansi penjualan) memiliki pengaruh yang lebih besar terhadap efektifitas penjualan dibandingkan $\mathrm{TX}_{2}$ (pengendalian internal). Hal ini terlihat dari nilai beta $\mathrm{TX}_{1}$ yaitu 0.416 dan memiliki nilai signifikan sebesar 0.000 .

\section{Uji F}

Pengujian ini dilakukan dengan dua cara yaitu quick look dan perbandingan nilai $\mathrm{F}_{\text {hitung }}$ dan $\mathrm{F}_{\text {tabel }}$ dengan hasil sebagai berikut:

Tabel 8.

Hasil Uji F

\begin{tabular}{llccccc}
\hline \multicolumn{7}{c}{ ANOVA $^{\mathbf{a}}$} \\
\hline \multirow{2}{*}{1} & Model & Sum of Squares & df & Mean Square & F & Sig. \\
\cline { 2 - 7 } & Regression & 737.130 & 2 & 368.565 & 29.517 & $.000^{\mathrm{b}}$ \\
\cline { 2 - 6 } & Residual & 1585.801 & 127 & 12.487 & & \\
\cline { 2 - 6 } & Total & 2322.9312 & 129 & & & \\
\hline
\end{tabular}

a. Dependent Variable: TY

b. Predictors: (Constant), $\mathrm{TX}_{2}, \mathrm{TX}_{1}$

(Sumber: Data Diolah Penulis Menggunakan Software SPSS 24 for Windows, 2020)

Berdasarkan perhitungan pada tabel 8 , hasil menunjukkan bahwa variabel $\mathrm{TX}_{1}$ dan $\mathrm{TX}_{2}$ secara bersama-sama memiliki pengaruh yang signifikan terhadap efektivitas penjualan di Darussyfa Mart. 


\section{Uji Koefisien Detereminasi}

Analisis koefisien determinasi adalah suatu analisis yang menunjukkan seberapa besar pengaruh antara variabel yang diteliti. Hasil uji koefisien determinasi dapat dilihat pada tabel dibawah ini:

Tabel 9.

Hasil Uji Koefisien Detereminasi

\begin{tabular}{|c|c|c|c|c|c|}
\hline \multicolumn{6}{|c|}{ Model Summary ${ }^{\mathrm{b}}$} \\
\hline Model & $\mathbf{R}$ & R Square & Adjusted R Square & $\begin{array}{l}\text { Std. Error of the } \\
\text { Estimate }\end{array}$ & $\begin{array}{l}\text { Durbin- } \\
\text { Watson }\end{array}$ \\
\hline 1 & $.563^{\mathrm{a}}$ & .317 & .307 & 3.534 & 1.116 \\
\hline $\begin{array}{l}\text { a. } \\
\text { b. }\end{array}$ & $\begin{array}{l}\text { Predicto } \\
\text { Depende }\end{array}$ & $\begin{array}{l}\text { Constant), } \\
\text { ariable: } \mathrm{TY}\end{array}$ & & & \\
\hline
\end{tabular}

Berdasarkan tabel diatas diketahui nilai $\mathrm{R}^{2}$ ( $R$ Square) dalam penelitian ini adalah 0,317 atau 31,7\% yang artinya kemampuan variabel-variabel independen dalam menjelaskan variasi variabel dependen sebesar $31,7 \%$, sedangkan sisanya sebesar $68,3 \%$ dipengaruhi oleh faktor lain diluar model ini yang tidak diteliti.

\section{PEMBAHASAN}

Berdasarkan hasil penelitian, sistem informasi akuntansi penjualan berpengaruh terhadap efektifitas penjualan. Hal ini didukung oleh Rachman (2011) yang meyatakan bahwa sistem informasi bukan hanya sebagai pengumpul data semata, lalu mengolahnya menjadi informasi berupa laporan keuangan saja, tetapi berperan lebih dalam menyediakan informasi bagi manajemen untuk fungsi perencanaan, alokasi sumber daya dan pengukuran atau pengendalian. Ini menunjukkan bahwa pengaturan sistem informasi akuntasi sangat penting dalam menjalankan suatu usaha. Selain itu, Radityo \& Zulaikha (2007) menyatakan bahwa sistem informasi merupakan seperangkat komponen yang saling berhubungan yang berfungsi mengumpulkan, memproses, menyimpan dan mendistribusikan informasi untuk mendukung pembuatan keputusan dan pengawasan dalam organisasi.

Penjualan menjadi salah satu kegiatan yang penting dalam perusahaan karena sumber utama pendapatan perusahaan berasal dari penjualan, kegiatan penjualan dapat dilaksanakan dengan baik jika didukung oleh sistem penjualan yang memadai. Sistem informasi yang memadai akan menghasilkan informasi-informasi penting yang sangat 
diperlukan oleh pimpinan dalam mengambil keputusan yang tepat demi kemajuan organisasinya.

Pengendalian internal pada penelitian ini juga memiliki pengaruh terhadap efektivitas penjualan di Darussyfa Mart, meskipun tidak lebih besar dibandingkan sistem informasi akuntansi penjualan. Penerapan pengendalian internal dapat mendukung ketahanan suatu usaha, dimana pengendalian (control) adalah mekanisme yang diterapkan untuk melindungi perusahaan dari resiko atau untuk meminimalkan dampak resiko tersebut pada perusahaan jika resiko tersebut terjadi (Mcleod \& Schell, 2008). Selain itu, pengendalian merupakan suatu sistem yang meliputi struktur organisasi beserta semua mekanisme dan ukuran-ukuran yang dipatuhi bersama untuk menjaga seluruh kekayaan organisasi dari berbagai arah (Sujarweni, 2015).

Hasil penelitian ini juga menunjukkan bahwa sistem informasi akuntansi dan pengendalian internal secara bersama-sama memiliki pengaruh yang signifikan terhadap efektivitas penjualan di Darussyfa Mart. Namun secara keseluruhan, kedua aspek tersebut hanya berpengaruh sebesar $31,7 \%$ terhadap efektivitas penjualan, sedangkan sisanya sebesar $68,3 \%$ dipengaruhi oleh faktor lain di luar model ini yang tidak diamati oleh peneliti. Hal ini sejalan dengan pernyataan yang disampaikan oleh Bachtiar (2012) bahwa sistem informasi akuntansi adalah suatu bagian atau prosedur yang saling berinteraksi dan berhubungan antara satu dengan yang lainnya dalam rangkaian secara menyeluruh yang peranannya sangat penting dalam kegiatan perusahaan sehingga dapat menghasilkan sebuah laporan yang distribusikan kepada para pengguna yaitu stakeholder, manajer perusahaan dan masyarakat yang membutuhkan.

\section{SIMPULAN}

Hasil penelitian menunjukkan bahwa $\mathrm{X}_{1}$ (sistem informasi akuntansi penjualan) memiliki pengaruh yang lebih besar terhadap efektifitas penjualan (Y) dibandingkan $\mathrm{X}_{2}$ (pengendalian internal). Namun variabel $X_{1}$ dan $X_{2}$ secara bersama-sama memiliki pengaruh yang signifikan terhadap efektivitas penjualan di Darussyfa Mart. Kemampuan variabel-variabel independen $\left(\mathrm{X}_{1}\right.$ dan $\left.\mathrm{X}_{2}\right)$ dalam menjelaskan variasi variabel dependen (Y) adalah sebesar 31,7\%, sedangkan sisanya sebesar 68,3\% dipengaruhi oleh faktor lain di luar model ini yang tidak diteliti. 


\section{DAFTAR PUSTAKA}

Bachtiar, E. (2012). Perancangan Sistem Informasi Akuntansi dengan Menggunakan Database Karyawan untuk Meningkatkan Keakuratan dalam Melakukan Perhitungan Penggajian pada PT. DIS. Jurnal Ilmiah Mahasiswa Akuntansi, 1(1), 86-89

Halim, A. (2012). Akuntansi Sektor Publik dari Anggaran hingga Laporan Keuagan dari Pemerintah hingga Tempat Ibadah. Jakarta: Salemba Empat

Mahmudi, M. (2010). Manajemen Kinerja Sektor Publik. Yogyakarta: UPP STIM YKPN

Rachman, R. F. (2011). Sistem Informasi Akuntansi Berbasis Komputer terhadap Kepuasan Pengguna Sistem Informasi Akuntansi pada PT. Multisarana Aditrans Jaya Surabaya. Skripsi. Universitas Pembangunan Nasional "Veteran" Jawa Timur

Radityo, D., \& Zulaikha, Z. (2007). Pengujian Model DeLone and McLone dalam Pengembangan Sistem Informasi Manajemen (Kajian Sebuah Kasus). Prosiding Simposium Nasional Akuntansi (SNA) X. Universitas Hasanudin Makasar

Mcleod, J. R., \& Schell, G. P. (2008). Sistem Informasi Manajemen. Jakarta: Salemba Empat

Romney, M. B., \& Steinbart, P. J. (2015). Sistem Informasi Akuntansi, Edisi ke-13. Jakarta: Salemba Empat

Sugiyono, S. (2017). Metode Penielitian Kuantitatif, Kualitatif dan R\&D. Bandung: Alfabet

Sujarweni, V. W. (2015). Sistem Akuntansi. Yogyakarta: Pustaka Baru Press

Swastha, B. (2012). Manajemen Penjualan. Yogayakarta: BPPEE-Yogyakarta

Wahyuningsih, N., Halim, A., \& Wulandari, R. (2015). Peranan Audit Oprasional dalam Menunjang Evektivitas Penjualan (Studi Empiris pada Perusahaan Daerah Air Minum Kabupaten Malang). Jurnal Riset Mahasiswa Akuntansi, 4(1), 1-10

Zamzami, F., Nusa, N. D., \& Faiz, I. A. (2016). Sistem Informasi Akuntansi. Yogyakarta: Gadjah Mada University Press 